05161148

5: $n x$

Fren TKC

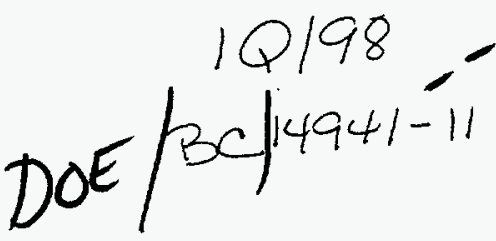

QUARTERLY TECHNICAL PROGRESS REPORT

(Tenth Quarter)

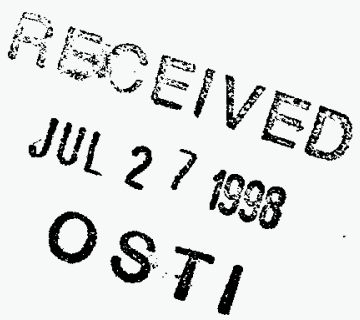

\title{
ADVANCED OIL RECOVERY TECHNOLOGIES FOR IMPROVED RECOVERY FROM SLOPE BASIN CLASTIC RESERVOIRS, NASH DRAW BRUSHY CANYON POOL, EDDY COUNTY, NM
}

\author{
DOE Cooperative Agreement No. DE-FC 22
}

Strata Production Company

P.O. Box 1030

Roswell, NM 88202

(505) 622-1127

Date of Report:

Award Date:

Anticipated Completion Date:

Award Amount for Current Fiscal Year:

Award Amount for Budget Period I:

Name of Project Manager:

Contracting Officer's

Representative:

Reporting Period:
April 30, 1998

September 25, 1995

September 24, 1998 - Budget Period I

September 25, 2001 - Budget Period II

$\$ 1,080,432$

$\$ 3,354,067$

Mark B. Murphy

Mary Beth Pearse

January 1, 1998 - March 31, 1998

US/DOE Patent Clearance is not required prior to the publication of this document. 


\section{DISCLAIMER}

Portions of this document may be illegible electronic image products. Images are produced from the best available original document. 


\section{OBJECTIVE}

The overall objective of this project is to demonstrate that a development program-based on advanced reservoir management methods - can significantly improve oil recovery at the Nash Draw Pool (NDP). The plan includes developing a control area using standard reservoir management techniques and comparing its performance to an area developed using advanced reservoir management methods. Specific goals are (1) to demonstrate that an advanced development drilling and pressure maintenance program can significantly improve oil recovery compared to existing technology applications and (2) to transfer these advanced methodologies to oil and gas producers in the Permian Basin and elsewhere throughout the U.S. oil and gas industry.

\section{SUMMARY OF TECHNICAL PROGRESS}

This is the tenth quarterly progress report on the project. Results obtained to date are summarized.

\section{Geostatistics and Reservoir Mapping}

New techniques correlating seismic attributes and reservoir parameters are currently under investigation at the Petroleum Recovery Research Center. Maps resulting from this work will be compared to the geostatistical maps generated previously. These multi-variate techniques will be in addition to the earlier linear cross-plots of amplitude versus porosity used to populate the interwell areas with porosity estimates.

Seismic attributes from several broad categories including frequency, reflection strength, phase, isochrons, and curvatures have been extracted from the 3D seismic data for the " $K$ " and " $L "$ intervals. During the next quarter, these attributes will be parsed through a fuzzy-curve algorithm to select those attributes which are most correlatable with porosity, water saturation, and other reservoir parameters of interest. This subset of attributes will be used to correlate reservoir properties at the wellbore to seismic attributes at the location of the wellbores through multi-variable linear regression and/or neural network (non-linear) analysis. When mathematical relationships between the attributes and wellbore parameters from wireline logs are established, maps of those reservoir properties will be computed for the location of each seismic bin (every $110 \mathrm{ft}$ ) across the NDP for the "K" and " $L$ " intervals.

\section{Reservoir Engineering}

The analysis of reservoir, seismic, and production data has led to an interpretation of the major reservoir compartments in the " $\mathrm{L}$ "Zone. Using a reservoir simulator model to match gas-oil ratio history and to estimate the reservoir pressure, bottomhole pressure (BHP) history was developed for each well. These data are presented in Table 1.

The BHP data were then used in a nearest-neighbor analysis to determine areas of the reservoir with common pressure characteristics (see Figure 1). The nearest neighbor analysis 
coupled with the cumulative production vs. rate analysis and geostatistical analysis presented in the Ninth Quarterly Report have provided an interpretation of the major reservoir compartments in the "L" Zone.

The current interpretation indicates a series of well defined compartments that are identified by production interference, seismic data, and pressure history. These compartments are shown in Figure 2 and are summarized in Table 2.

There is good correlation of the boundaries between the observed data and the seismic interpretation. Boundaries are interpreted to exist where there is a large contrast in amplitudes, from a high negative amplitude area to a low negative amplitude area. This interpretation is supported by the analysis of instantaneous frequencies prepared earlier by Dr. Bob Hardage. His interpretation indicated compartments that were more complex than this interpretation, but may be more accurate in the light of reduced recovery efficiency of wells in areas he described as "highly compartmentalized." This may indicate that some individual sands are continuous from well to well and some sands are very limited in their aerial extent.

This work will continue for the purpose of aiding in the prediction of drilling locations with minimal pressure depletion and compartments that have not been drained. The NDP \#36 Well will test this theory by drilling a directional/horizontal well into the seismic anomaly north of NDP \#15. This pod may be a separate compartment that is defined by a large contrast in seismic amplitudes surrounding this anomaly.

\section{Reservoir Characterization/Reservoir Simulation}

Activities of the Reservoir Characterization/Simulation Team for the first quarter of 1998 were focused on completing of the evaluation of the Apprentice/Merlin reservoir simulator from Gemini Solutions, Inc.

The target for this software evaluation is NDP \#36, the planned horizontal well to be located in Blocks 11 and 12. As stated in the last quarterly report, the purpose of the evaluation is to determine:

- whether the Apprentice/Merlin simulator can handle horizontal wells with fractures

- what the initial conditions are in the drainage area of NDP \#36

- what recoveries can be expected from the proposed configuration of NDP \#36

- whether additional fractures would provide additional cost-benefit

During this quarter three models of increasing complexity were developed. Each had four layers corresponding to the $\mathrm{L}_{a}, \mathrm{~L}_{b}, \mathrm{~L}_{c}$, and $\mathrm{L}_{\mathrm{d}}$ intervals, respectively. They differed in their treatment of the induced fractures. The simplest model treated the four planned fractures as a column of $10-$ foot gridblocks; the most complex model treated them as a column of one-foot blocks. We were able to make runs through historical production data with the coarse model, but not the refined models. A catalogue of Apprentice/Merlin runtime problems has been generated for discussion with the vendor. 


\section{Miscible Recovery Simulations}

Prior work on the Nash Draw Brushy Canyon pilot area produced simulations with a qualitative match of history to March, 1997. These results and data were used as the basis of simulations of miscible injection in the pilot area. Although a different reservoir simulator was required for the miscible injection study, the history match for the miscible cases was qualitatively the same as that previously obtained even though lower hydrocarbon gas density was used in the miscible gas study. History match for gas production from the five wells in the pilot area (NDP Wells \#1, 5,6,10, and 14) show typical solution gas drive performance with initial high GORs decreasing as the reservoir is depleted. Since the pilot location for this study is no longer under consideration for the field trial, further history matching was not performed, since it is likely only minor differences in results would follow. Instead, several predictions of miscible and immiscible injection were performed to obtain qualitative results for these different recovery mechanisms.

Several prediction simulations were performed with carbon dioxide $\left(\mathrm{CO}_{2}\right)$ for both miscible and immiscible injection scenarios. For the miscible injection cases, simplifying assumptions were made because no laboratory data were available. In particular, the miscible injectant was assumed to have properties of pure carbon dioxide and to be first-contact miscible with the reservoir oil. To compare the different prediction cases, oil production was-calibrated by adjusting the flowing bottomhole pressure at the beginning of the prediction cases so that the oil production rate was similar to the field-observed rates. With the constant bottomhole pressure as a boundary condition, predictions were then made from the end of history for 11 years to March 1,2008. Injection was assumed to begin immediately after the end of the history match, although in reality a delay of at least 2 years would be required for project implementation. Injection was based on $120 \mathrm{MSCF} / \mathrm{D}$ of gas injectant - either miscible or immiscible. This volume was based on the volume of immicible gas required to maintain pressure in the reservoir. A water-alternating-gas (WAG) scenario was also simulated. In this case the injection bottomhole pressure was limited to 5000 psi with a WAG ratio of about $4: 1$ water to carbon dioxide.

Simulations compared a base case of continued operations with no injection to a total of 9 prediction cases for various recovery scenarios: (1) convert NDP \# 1 to injector - $120 \mathrm{MSCF} / \mathrm{D} \mathrm{CO} \mathrm{C}_{2}$ miscible, (2) convert NDP \# 5 to injector - $120 \mathrm{MSCF} / \mathrm{D} \mathrm{CO} \mathrm{CO}_{2}$ miscible, (3) convert NDP \# 6 to injector - $120 \mathrm{MSCF} / \mathrm{D} \mathrm{CO}_{2}$ miscible, (4) convert NDP \# 10 to injector - $120 \mathrm{MSCF} / \mathrm{D} \mathrm{CO}_{2}$ miscible, (5) convert NDP \# 14 to injector - $120 \mathrm{MSCF} / \mathrm{D} \mathrm{CO}_{2}$ miscible, (6) infill injector - $120 \mathrm{MSCF} / \mathrm{D} \mathrm{CO}_{2}$ miscible, (7) infill injector - 4:1 WAG, (8) infill injector - $60 \mathrm{MSCF} / \mathrm{D} \mathrm{CO}_{2}$ miscible, and (9) infill injector - 120 MSCF/D immiscible injection. The infill injector was located at the center of the pilot area between wells NDP \# 1, 6, 10, and 14 .

Simulation results for miscible injection in the NDP pilot area indicate that carbon dioxide injection may well be a viable alternative for improved oil recovery for this field. For the eight different $\mathrm{CO}_{2}$ miscible scenarios, increased oil recovery was observed compared to a continued operations case. Increased oil recoveries ranged from a low of 40 MSTB to a high of 110 MSTB or an increase in recovery of from $2-5 \%$ of OOIP. In contrast, immiscible hydrocarbon gas injection showed little increase in oil recovery. These results coupled with a reasonable recovery per MCF of $\mathrm{CO}_{2}$ injected indicate that further investigations should be made into $\mathrm{CO}_{2}$ miscible injection. 
To continue work on a new pilot area several steps need to be taken. Several assumptions which were made in the initial miscible simulations need to be validated. In particular, even if firstcontact miscibility does not occur, swelling of the oil from immiscible $\mathrm{CO}_{2}$ injection may also result in significant oil recoveries. Reservoir fluid behavior tests should be performed, especially with carbon dioxide as one of the components. Better characterization of the reservoir in the vicinity of the new pilot area should be obtained to assess the practicality of initiating an injection test. Based on these preliminary results, $\mathrm{CO}_{2}$ breakthrough should occur in less than one year even in the most optimistic situation. This indicates that a well-designed and simulated pilot could provide timely information for use in a full-field implementation.

\section{Technology Transfer}

Transferring technical information generated during the course of this project is a prime objective of the project. Toward this objective, Strata has participated in several meetings and workshops to promote the dissemination of information from the project. A summary of technology transfer activities during this quarter is outlined below.

SPE Paper - A paper titled "Reservoir Characterization as a Risk Reduction Tool at the Nash Draw Pool," that was presented at the 1997 SPE Annual Technical Conference and Exhibition was also presented at the 1998 Permian Basin Oil and Gas Recovery Conference in Midland, Texas on March 23-26, 1998.

SPE Paper 39775- A paper entitled "Using Reservoir Characterization Results at the Nash Draw Pool to Improve Completion Design and Stimulation Treatments." was presented at the 1998 Permian Basin Oil and Gas Recovery Conference in Midland, Texas on March 23-26, 1998.

Core Workshop - Nash Draw core and associated material was exhibited at a core workshop held in Midland, Texas on February 26, 1998. The workshop was sponsored by the Permian Basin Section/SEPM for cores from DOE projects in the Permian Basin.

Internet Homepage: The new address of the Website for the Nash Draw project is: http://baervan.nmt.edu/REACT/Links/nash/strata.html. This site includes an interactive map of logs and production data for the project and the most recent annual (second annual) report including graphics. 
Table 1. Bottom hole pressure vs. gas-oil ratio.

\begin{tabular}{|c|c|c|c|c|c|c|c|c|c|c|c|c|}
\hline$\frac{\text { WELL }}{\#}$ & $\begin{array}{l}\text { GOR } \\
1993 \\
\end{array}$ & $\begin{array}{l}\text { BHP } \\
\text { PSI }\end{array}$ & $\begin{array}{l}\text { GOR } \\
1994\end{array}$ & $\begin{array}{l}\text { BHP } \\
\text { PSI }\end{array}$ & $\begin{array}{l}\text { GOR } \\
1995\end{array}$ & $\begin{array}{l}\text { BHP } \\
\text { PSI }\end{array}$ & $\begin{array}{l}\text { GOR } \\
1996\end{array}$ & $\begin{array}{l}\text { BHP } \\
\text { PSI }\end{array}$ & $\begin{array}{l}\text { GOR } \\
1997\end{array}$ & $\begin{array}{l}\text { BHP } \\
\text { PSI }\end{array}$ & $\begin{array}{c}\text { GOR } \\
1998\end{array}$ & $\begin{array}{l}\text { BHP } \\
\text { pSI }\end{array}$ \\
\hline 1 & $2.85^{\circ}$ & 2100 & 8.54 & 1100 & 10.95 & 800 & 9.56 & 150 & 8.35 & 100 & 4.37 & 50 \\
\hline 5 & 1.28 & 2800 & 6.38 & 1250 & 8.81 & 950 & 6.29 & 1275 & 8.47 & 950 & 9.01 & 900 \\
\hline 6 & 1.45 & 2800 & 6.10 & 1280 & 7.64 & 1050 & 6.61 & 1225 & 6.66 & 1250 & 8.57 & 950 \\
\hline 9 & 1.68 & 2800 & 3.01 & 1950 & 3.82 & 1750 & 12.06 & 400 & 11.60 & 300 & 8.59 & 200 \\
\hline 10 & 0.77 & 2900 & 4.72 & 1550 & 7.23 & 1100 & 6.90 & 1200 & 13.52 & 500 & 14.06 & 400 \\
\hline 11 & 0.96 & 2900 & 1.40 & 2700 & 4.82 & 1525 & 4.08 & 1800 & 5.26 & 1400 & 4.81 & 1500 \\
\hline 12 & & & & & & & & & 13.03 & 800 & 15.98 & 500 \\
\hline 13 & 1.07 & 2900 & 1.94 & 2400 & 4.96 & 1500 & 5.71 & 1400 & 6.16 & 1300 & 8.40 & 960 \\
\hline 14 & 1.05 & 2900 & 5.79 & 1470 & 7.91 & 1050 & 12.69 & 400 & 10.81 & 300 & 9.34 & 200 \\
\hline 15 & & & 1.92 & 2400 & 3.91 & 1725 & 5.74 & 1400 & 10.20 & 800 & 13.39 & 600 \\
\hline 19 & & & 1.54 & 2600 & 6.87 & 1200 & 8.23 & 1000 & 5.94 & 1330 & 6.31 & 1250 \\
\hline 20 & & & 2.96 & 2000 & 6.09 & 1300 & 3.80 & 1525 & 6.21 & 1300 & 7.59 & 1100 \\
\hline 23 & & & & & 5.10 & 1480 & 7.10 & 1120 & 18.56 & 500 & 20.77 & 400 \\
\hline 24 & & & & & 1.71 & 2500 & 3.85 & 1750 & 4.64 & 1550 & 4.26 & 1620 \\
\hline 25 & & & & & & & 3.75 & 1760 & 4.45 & 1600 & 7.17 & 1125 \\
\hline 29 & & & & & & & & & 7.00 & 1150 & 9.38 & 860 \\
\hline 38 & & & & & & & & & 3.71 & 1750 & 5.59 & 1400 \\
\hline
\end{tabular}


Table 2. Compartmentalization Interpretation

\begin{tabular}{|c|l|}
\hline $\begin{array}{c}\text { Wells in Common } \\
\text { Compartments }\end{array}$ & \multicolumn{1}{|c|}{ Comments } \\
\hline $\begin{array}{c}1,6,9,10,12,14,19, \\
20,23,25,29 \\
\& 38\end{array}$ & $\begin{array}{l}\text { This area exhibits communication between wells, and later wells such } \\
\text { as \#12, 29, \& 38 exhibited partial pressure depletion and high initial } \\
\text { GORs. }\end{array}$ \\
\hline 5 & $\begin{array}{l}\text { This well does not exhibit major communication with neighboring } \\
\text { wells. }\end{array}$ \\
\hline $11 \& 13$ & $\begin{array}{l}\text { These wells do not exhibit major communication with neighboring } \\
\text { wells. }\end{array}$ \\
\hline 15 & $\begin{array}{l}\text { May have minor communication with \#23, which would indicate a } \\
\text { trend through \#15, 23, 29, \& 38. }\end{array}$ \\
\hline 24 & \begin{tabular}{l} 
This well does not exhibit communication with neighboring wells. \\
\hline
\end{tabular} \\
\hline
\end{tabular}




\begin{tabular}{|l|}
\hline Legend \\
$2800+$ \\
2590.91 to 2800 \\
2381.82 to 2590.91 \\
2172.73 to 2381.82 \\
1963.64 to 2172.73 \\
1754.55 to 1963.64 \\
1545.45 to 1754.55 \\
1336.36 to 1545.45 \\
1127.27 to 1336.36 \\
918.182 to 1127.27 \\
709.091 to 918.182 \\
500 to 709.091 \\
\hline
\end{tabular}

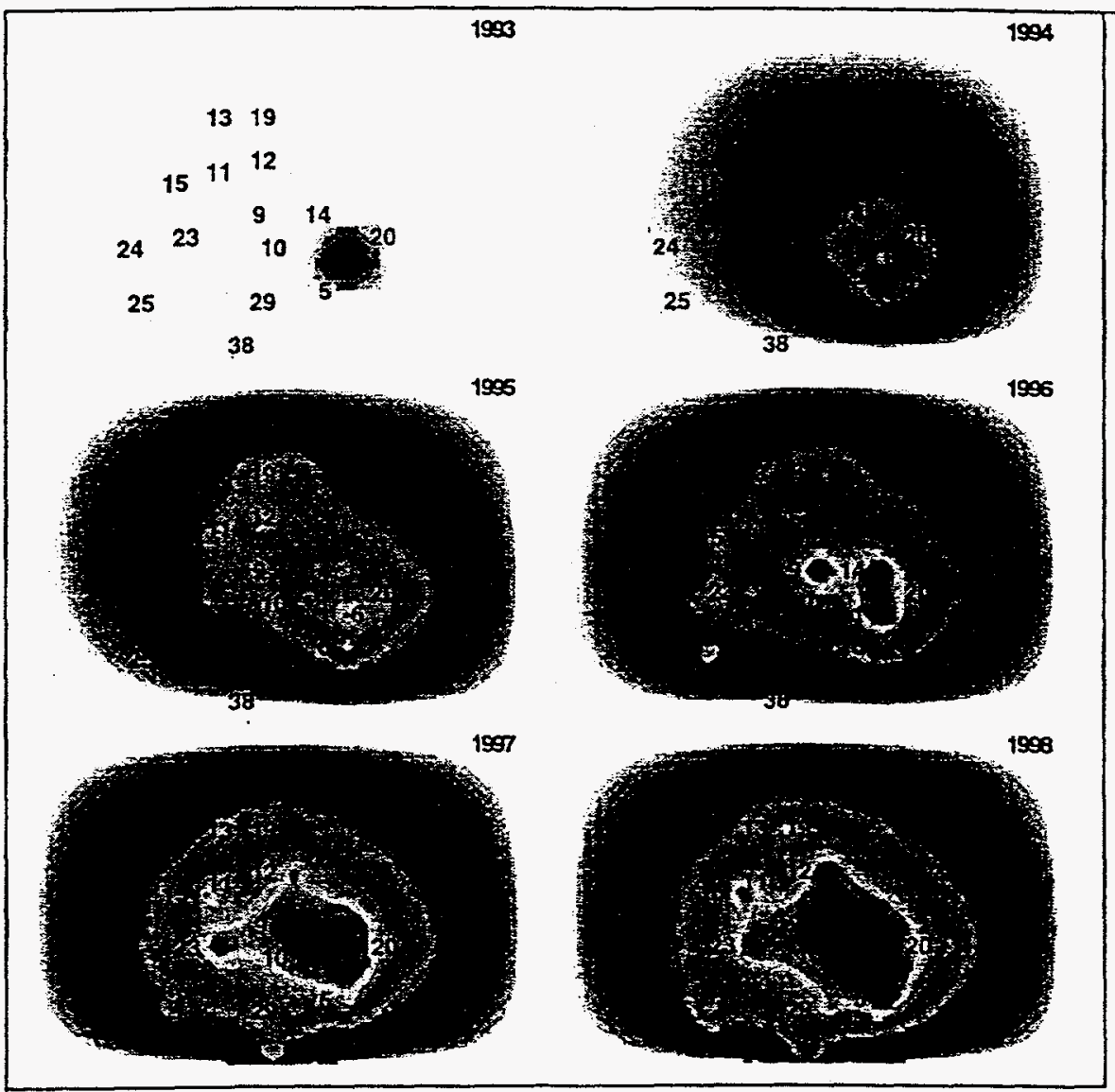

Figure 1. Nearest neighbor analysis of estimated bottom hole pressure. 


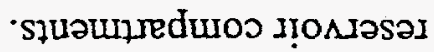

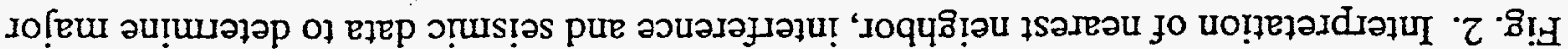

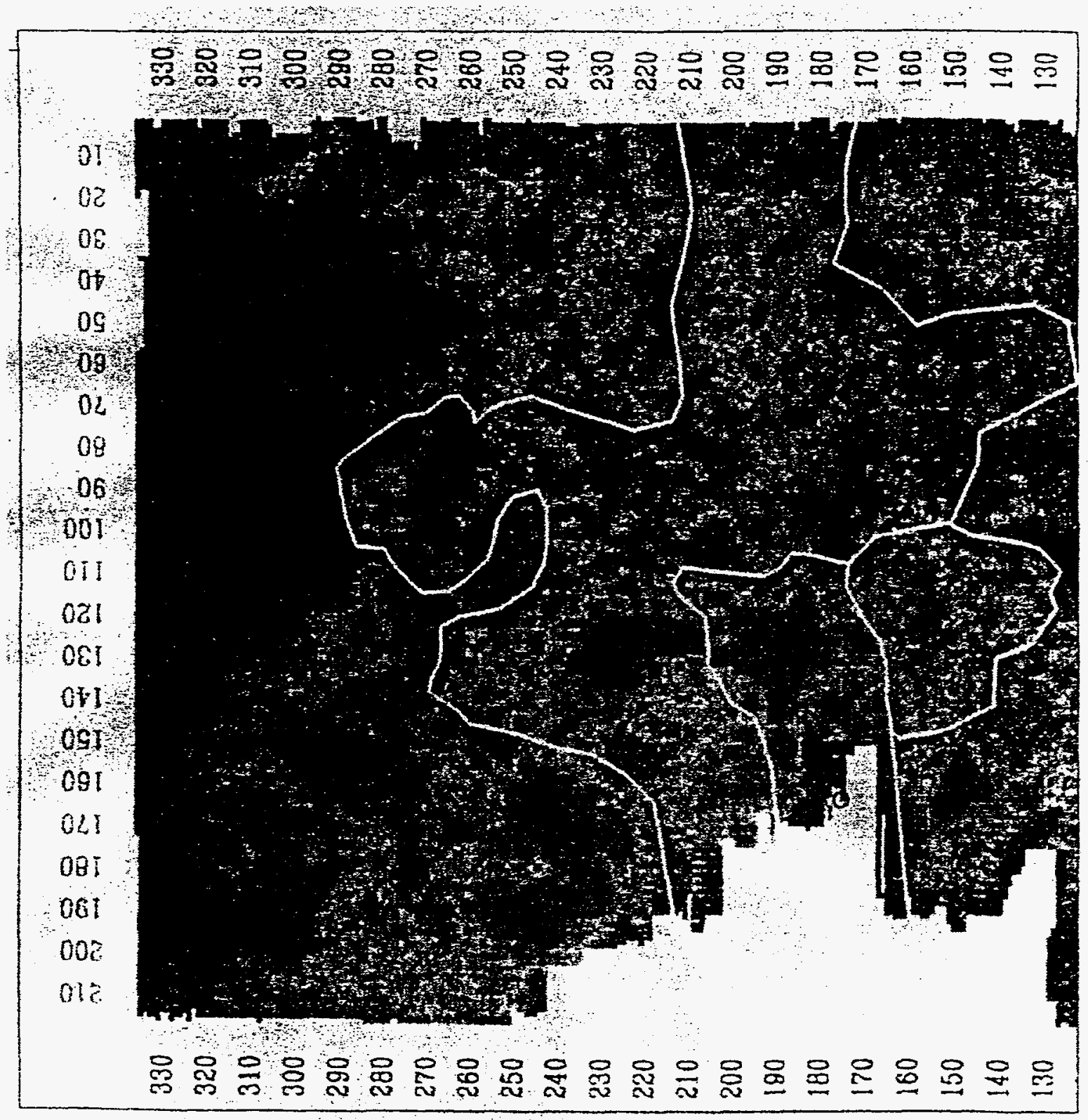

